\title{
Unemployment Outflow and Unemployment Insurance Taxes
}

\author{
Štěpán Jurajda* \\ CERGE-EI
}

April 22, 1999

\begin{abstract}
The system of Unemployment Insurance (UI) financing in the US draws its funds from a payroll tax on employers and varies the tax rate according to the individual employer's layoff history. There exists extensive evidence on the effect of this so-called experience rated tax on layoff decisions. However, since firms are liable for each dollar of regular UI benefits paid to laid off former employees, experience rating may also affect recall behavior. The present study therefore measures the effect of the UI financing system on the duration of unemployment. Using duration data is essential since tax charges to the firm vary over the duration of unemployment spells. Empirical results based on data with various sources of variation suggest that higher layoff tax costs shorten the duration of recall unemployment.
\end{abstract}

\footnotetext{
*I would like to thank John Ham, Frederick Tannery, and Randall Filer for their help and valuable suggestions. Special thanks go to John Engberg for generously providing the raw data and for his helpful comments. Comments are welcome at stepan.jurajda@cerge.cuni.cz . The usual disclaimer applies.
} 


\section{Introduction}

The method of financing Unemployment Insurance (UI) in the United States is unique among the countries of the world. Where other governments usually draw funds from various sources and tax all employers uniformly, the U.S. system of UI financing draws its funds from a payroll tax on employers and varies the tax rate according to the individual employer's layoff history. The tax schedule which makes more layoffs result in a higher UI tax rate is called experience rating. What matters for the firm's liability to the UI system is the amount of collected UI benefits of the workers laid off by the firm. In all states, however, payroll taxes are only partially experience rated, i.e. many firms are not responsible for the full amount of the UI benefits collected by their workers. In particular, firms which are at the maximum or minimum UI tax rate are not experience rated since a marginal change in the dollar amount of benefits paid to their workers has no effect on their future UI tax rate.

Feldstein (1976) was first to discuss the effect of UI financing on employment. He argued that imperfect experience rating makes firms more likely to use temporary layoffs and recalls since these firms contribute less in taxes than the full amount of UI benefits paid to the unemployed worker. The U.S. government therefore subsidizes these spells of unemployment and it may be optimal for firms with high demand fluctuations to lay off workers on the agreement of future recall. Feldstein's work started a new strand of empirical research measuring the effect of experience rating on (temporary) layoffs. Two papers in this literature are Card and Levine (1994) and Anderson and Meyer (1994). They both use cross-sectional data on individual workers to quantify how the degree of experience rating affects the incidence of layoffs. They differ in how they construct the measure of experience rating. In order to measure the firm level of experience rating accurately, one ideally needs the firm-specific UI tax rates. In absence of these one has to rely on industry-specific proxies of experience 
rating. ${ }^{1}$ Card and Levine (1994) use a state-industry-specific measure of experience rating and estimate that $50 \%$ of temporary layoffs during economic downturns is caused by incomplete experience rating. Anderson and Meyer (1994) are able to use the firm-specific UI tax rates. While they confirm previous results they also point to the importance of dealing with endogeneity of the tax incentives. One would like to isolate the effect of UI taxes on firm's behavior. Each firm, however, chose its position on the tax schedule by its past layoff decisions and so determines the tax rate it will face.

The existing studies therefore imply a strong effect of experience rating on temporary layoffs. A large fraction of such layoffs end in recall (see e.g. Katz and Meyer, 1990a). The contribution of this paper is to address an issue to the best of our knowledge ignored in the existing literature and focus on the effect experience rating might have on recall behavior. The intuition is simple. A firm which lays off a worker will face an increase in its future UI taxes for each dollar of regular UI benefits paid to an unemployed worker (unless this firm already is at the maximum tax rate). In case of temporary layoffs, one would therefore expect the firm to continuously compare the cost of keeping a worker on layoff to the cost of re-employment. This would suggest that layoff costs stemming from experience rating will, ceteris paribus, make firms recall workers earlier than they would otherwise. We first formalize this intuition using a theoretical model and then measure the effect empirically using a duration model. To differentiate between the effect of experience rating on recall unemployment and on permanent layoffs, we estimate a competing risk duration model for recalls and new jobs.

The choice of duration econometrics is motivated by the extensive variation in experience rating occurring over the duration of individual unemployment spells. First, the (weekly) dollar amount paid in UI benefits and charged to the firm is a function of elapsed unemployment duration. Firms' tax costs are zero once benefits are exhausted or when the worker's

\footnotetext{
${ }^{1}$ See Section 3 for a detailed discussion of this issue.
} 
UI is covered by some of the extended benefits programs. Second, laid off workers not eligible for UI compensation do not bring any additional charges to the firm. Third, as pointed out by Burgess and Low (1992), UI benefit are charged to a UI base period employer, not necessarily the most recent employer. ${ }^{2}$ Fourth, a worker may typically be laid off at no cost as long as she has an active UI claim. ${ }^{3}$ Even a firm that is fully experience rated in terms of the usual definition can take advantage of these additional subsidies to layoffs. It is only duration data on individual employment histories that enables us to take these additional sources of imperfect experience rating into account.

The data analyzed in this paper consists of the Trade Adjustment Assistance (TAA) dislocated workers survey augmented with information on the trigger dates of various extended benefit programs. The trigger dates are coded for over five years for seven states. Experience rating is an inherently firm-specific phenomenon. Using a sample of unemployed workers for studying effects of UI taxation on layoff behavior would be far from ideal because such sample does not include information on those workers who were not laid off. ${ }^{4}$ A survey of dislocated workers is, on the other hand, suitable for our analysis, since we focus on the effect of experience rating on recalls conditional on layoff.

The empirical results of this paper are suggestive of behavioral importance of experience rating for recall behavior. A higher weekly UI tax cost of keeping a worker on layoff raises the recall probability and therefore shortens recall unemployment. This effect is more pronounced for workers who had been previously recalled, suggesting, as one might expect, that firms which use the strategy of temporary layoffs and recalls to adjust employment are more

\footnotetext{
${ }^{2}$ The UI base period is typically defined as the first four of the five quarters preceding the start of unemployment. A firm that lays off workers within the first quarter of employment is therefore not charged for the layoffs unless the worker was employed in the firm during the base period.

${ }^{3}$ Layoffs occurring during an existing worker's UI claim are, in most states, charged to all base period employers, not necessarily to the current employer.

${ }^{4}$ The ideal data set would consist of a sample of firms matched with detailed records describing individual employment histories of the firms' workers. Such data sets are extremely scarce. The sample of firms collected by Burgess and Low (1992) is the only such data set we are aware of.
} 
sensitive to UI taxes. Finally, we do not find any significant effect of experience rating on the probability of finding a new job. This, we believe, is reassuring for our recall hazard estimates.

The paper proceeds as follows. Section 2 discusses a model of firms' layoff and recall decisions. The data set is described in Section 3. Section 4 presents the econometric techniques, and describes the estimation procedure together with the empirical results. Section 5 concludes.

\section{A Two-period Model of Layoffs and Recalls}

The imperfect experience rating of UI financing has motivated two main strands of theoretical research. The first treats UI taxes as an adjustment cost (e.g. Baily, 1977). A typical adjustment cost model would imply that more generous UI coverage leads to lower risks of layoff since firms are at least partially responsible for the UI benefits paid to their former employees. The second strand of research started with Feldstein's 1976 implicit contract analysis. In the contract theory analysis firms are assumed to offer employment contracts which provide workers with a market-determined level of expected utility. In these models workers with more UI entitlement are better protected against prolonged spells of unemployment and the layoff probability is therefore an increasing function of the available UI compensation. All of these models predict that a higher degree of experience rating leads to a lower layoff probability, but they differ in their prediction of the effect of available UI compensation. In a simple two-period adjustment cost model analyzed below we demonstrate how UI compensation and experience rating interact in affecting the reemployment decisions of firms. The model introduces dependence of firm's decisions on worker's behavior in unemployment, an optimization dimension ignored in previous theoretical work.

A typical job search model (see e.g. Mortensen, 1977) derives the escape rate out of 
unemployment $q$ as a function of the optimally chosen reservation wage. Workers with higher amount of UI coverage $B$ are less likely to find new jobs as their optimal reservation wages are increasing in the amount of UI. (We assume that workers' UI entitlement does not expire and we control for the generosity of UI using only the amount of benefits.) Job search theory therefore predicts that the optimal quit rate $q(B)$, i.e. the likelihood that the unemployed worker finds a job with an alternative employer, is decreasing in $B$, i.e. $q^{\prime}(B)<0$. Consider the optimal employment strategy of a firm taking into account workers' optimal job search based on the available UI compensation $B=r w$, where $w$ is the worker's wage and $r$ denotes the replacement ratio of the UI compensation formula (the ratio of UI benefits to previous wage). The source of uncertainty for firms will be in new draws from a time constant distribution $f(M)=F^{\prime}(M)$ of marginal revenue product $M$ of its workers. ${ }^{5}$ As our focus is on temporary layoffs, the firm is assumed to have a stable permanent labor force. The worker-firm attachment arises as a consequence of training costs $C$ the firm incurs when hiring a new worker. ${ }^{6}$

In both mornings there is a new draw of the marginal revenue product $M$ and the firm decides on the employment status of its workers. Following the firm's decision, laid-off workers search for new jobs. Production and collection of UI benefits consume the rest of the day. Let $\beta$ denote the discount factor and let $x$ be the degree of experience rating (i.e. the firm's marginal tax cost for a dollar of UI benefits paid to a laid off former employee). The wage $w$ is fixed as in the adjustment cost models of Baily (1977) or Card and Levine (1994). These assumptions greatly simplify the analysis, while they retain all the intuition

\footnotetext{
${ }^{5}$ Changes in $M$ are assumed to be caused by demand driven price fluctuations. The firm therefore observes new values of marginal revenue product even for workers on layoff.

${ }^{6}$ See Feldstein (1976) and Card and Levine (1994) for models with labor force permanently attached to the firm based on firm specific human capital.
} 
of the model. ${ }^{7}$ Given our assumptions we can write the firm's profit value function $\pi$ as

$$
\begin{array}{r}
\pi=\max \left\{M-w+\beta \int_{w}^{\infty}(\hat{M}-w) d F(\hat{M}),(1-q(r w))\left[-x r w+\beta \int_{w}^{\infty}(\hat{M}-w) d F(\hat{M})\right]\right. \\
\left.+q(r w) \beta \int_{w+C}^{\infty}(\hat{M}-w) d F(\hat{M})\right\}
\end{array}
$$

If the worker is hired, the firm's profits consist of the first-period profit $M-w$ and the discounted expected second-period profit from having the worker available. In the second period the firm hires whenever the value of the marginal revenue product exceeds that of the fixed wage. If the worker is not hired in the first period, she either stays unemployed with probability $(1-q(r w))$, in which case the firm incurs the UI tax costs of $x r w$ and has the worker available for work in the second period, or she finds a new job with another employer with probability $q(w r)$. When not having a worker available, the firm only hires a new worker in the second period when marginal revenue product exceeds the sum of the training cost and wage.

One can show that there exists an optimal stopping rule $m$, such that if the firm decides to hire at $m$ in the first period then it will decide to hire at all $M>m$. The optimal stopping value of marginal revenue product is implicitly defined by the equality of profits evaluated at the optimal decision rule in the two alternative states, employment and non-employment. In either state, the firm expects to make $\beta E[M-w \mid M>w]$ in the second period and determines the optimal cutoff value for the first period by equating the profit from hiring the worker at the cutoff, $m-w$, with the cost of not hiring. For a laid-off worker who enjoys unemployment benefits, profits equal $-x r w$, the UI cost of layoff, while for a worker who finds a new job the firm evaluates the expected decrease in future profits resulting from losing the worker to another firm as $-\beta E[M-w \mid w<M<w+C]$. It follows that

$$
\frac{\partial m}{\partial x}=-w r(1-q(w r))<0
$$

\footnotetext{
${ }^{7}$ See Jurajda (1998) for a dynamic programming analysis of an infinite period model allowing for gradual exhaustion of benefits.
} 
so that a higher degree of experience rating decreases $m$ and therefore increases the optimal recall rate $1-F(m)$. The sign of $\frac{\partial m}{\partial r}$, however, is indeterminate:

$$
\frac{\partial m}{\partial r}=-x w(1-q(w r))+q^{\prime}(w r)\left[x w r-\beta \int_{w}^{w+C}(M-w) d F(M)\right] .
$$

If firms were not taxed for layoffs, i.e. if $x=0$, the cutoff value would be increasing in $r$ as having a worker with higher UI implies a lower probability of losing such worker and incurring training costs. On the other hand, even if there are no training costs, the sign remains indeterminate because higher replacement ratio makes the likelihood of incurring the UI costs of layoff lower.

\section{Data Description}

The sample of individual employment histories used in this paper comes from the Trade Adjustment Assistance (TAA) dislocated workers survey. The data was collected in seven states $^{8}$ and covers approximately 3.5 years of employment histories for each worker between 1974 and 1978. The TAA program was designed to compensate workers harmed by market fluctuations resulting from a rise in imports. ${ }^{9}$ The initial data was collected using retrospective interviews with individuals who became unemployed in the mid $1970 \mathrm{~s}$ and this information was merged with UI claims records. The TAA recipients were entitled to more generous UI compensation compared to the regular UI. ${ }^{10}$ The sample includes both regular UI recipients and TAA recipients. The combination of TAA and UI recipients makes for a rich variation in UI entitlement and benefits. Further, the sample covers a period with many dramatic changes in UI entitlement, caused by various extended coverage programs being triggered on and off. The data set as well as detailed information on the extended benefits programs is described in Corson and Nicholson (1981) and Jurajda (1998).

\footnotetext{
${ }^{8}$ California, Indiana, Massachusetts, New York, Ohio, Pennsylvania and Virginia.

${ }^{9}$ The program was amended several times and remained active thorough the 1990's.

${ }^{10}$ Their entitlement was extended by up to 52 additional weeks of UI coverage. Also, their dollar benefits amount was calculated as $70 \%$ of their previous wages as opposed to the $50 \%$ typical of regular UI.
} 
Table 1: Individual and Spell Characteristics

Number of Individuals $=1245 \quad$ Number of Spells $=2050$

\begin{tabular}{||lll|ll||}
\hline Variable & Mean & Std.Dev. & Dummy Variable & Mean \\
\hline Education & 11.0 & $(2.66)$ & Union & 0.47 \\
Age & 37.1 & $(12.5)$ & Previous Recall & 0.45 \\
Previous Wage & 1.94 & $(1.04)$ & UI Non-recipient & 0.16 \\
UI Entitlement & 43.2 & $(22.4)$ & & \\
UI Benefits & 0.83 & $(0.51)$ & & \\
Unemployment Duration & 36.4 & $(47.6)$ & & \\
\hline
\end{tabular}

From the initial sample of 1501 individuals we omit the 148 cases in which the initial unemployment spell was in fact a period of reduced hours. Further, inconsistent and missing data records are deleted, as well as observations from industries for which we were unable to calculate our measure of experience rating (see below), yielding a sample of 1245 workers. The data includes the level of initial entitlement and benefits only for the first unemployment spell. Entitlement and benefit levels for the subsequent unemployment spells are therefore imputed using the state specific UI laws and the individual employment histories. ${ }^{11}$ Table 1 presents the data means at the first week of each of 2050 spells. The standard deviations of the UI variables are quite high even though they only reflect the cross-sectional variation in the first week of each spell. Additional time variation is a consequence of the extended coverage programs, which change the generosity of UI compensation even for spells in progress.

Next, we present the main features of the UI financing systems of the sample states and discuss how we measure the degree to which firms are responsible for layoffs. UI benefits are financed by payroll taxes and the level of taxes depends on the firm's taxable payroll and UI tax rate. There are two main types of UI payroll tax schedules used in the U.S., the so

\footnotetext{
${ }^{11}$ We take the level of initial entitlement in the first unemployment spell as given and follow each individual over time to determine the level of entitlement in each week using information on the individual's employment history, the reason for job separation, the level of wages, UI eligibility requirements and the effective trigger dates of extended benefits programs. In doing so we assume that workers are able to correctly calculate their UI compensation even in future UI claims. For further details see Jurajda (1998).
} 
called reserve ratio system and the benefit ratio system. ${ }^{12}$ The state UI payroll tax systems have been described in detail in Card and Levine (1992). Under all UI tax systems, the firm's tax rate is an increasing function of the amount of UI benefits paid to laid off former employees. Most of the previous work on experience rating therefore used the fraction of a dollar paid in UI benefits to a laid off worker that the firm has to pay in future taxes as the relevant measure of experience rating. This marginal tax cost (MTC) measure is ideally constructed by taking firm's tax rate, locating the position on the state tax schedule and computing what the discounted future stream of taxes paid by the firm for a dollar increase in UI benefits will be, given the expected payroll growth. The degree to which the MTC is less than one is a measure of the subsidy of the state UI tax system to keeping a laid off worker unemployed.

It would be ideal to use firm level data on the UI tax rates instead of relying on stateindustry proxies typically constructed from insured unemployment rates, as firm level taxes vary considerably within industries. Similar to almost all data sets used in the experience rating literature, the TAA sample does not include information on the firm level tax rate and we construct measures of experience rating using the formulas described in detail in Card and Levine (1992). Yet, we are able to at least partially improve upon the quality of the imputation procedure by using the actual average industry-state specific UI tax rates, instead of constructing their proxies from the insured unemployment rates as previous studies $\operatorname{did}^{13}$ 
manufacturing, construction, services, finance, and retail trade. It was impossible to calculate the MTC for other industries and we dropped those observations which resulted in a loss of approximately $3 \%$ of the data. The MTC is constructed from year specific tax schedules and using annual values of the industry and state specific UI tax rate and employment growth. In order to avoid confounding changes in tax rates with business cycle effects in the estimation, we condition on a set of year dummies (see Card and Levine, 1994, for discussion of this issue). Table 2 reports the estimated values of MTC for the present sample.

The combination of TAA and UI recipients leads to a rich variation not only in UI entitlement and benefits, but also in the degree of experience rating. TAA firms are not responsible for UI benefits paid to their workers and that allows for comparison of workers from experience rated firms within the industry classes where TAA petitions were approved. ${ }^{14}$ The TAA workers are concentrated in manufacturing and constitute $57 \%$ of the sample's unemployment spells.

Existence of the UI benefit year is another source of variation in experience rating. The UI benefit year starts with the initial UI claim at which moment the entitlement for that year is determined based on the eligibility requirements. The eligibility requirements are in turn based on worker's employment history during the so called base period. UI benefits are then charged to a base period employer, not necessarily the most recent employer. Since base period is typically defined as the first four of five preceding quarters, a firm which lays off workers within the first quarter of employment is not charged for the layoffs unless the worker was employed in the firm during the base period. Furthermore, layoffs occurring during the worker's UI claim are, in most states, charged to all base period employers. A newly hired worker may therefore be laid off at no cost as long as she has an active UI claim. Even a firm which is fully experience rated in terms of the usual definition can take advantage of

\footnotetext{
${ }^{14}$ Such comparison is interesting as most previous studies analyzing the effect of UI taxes on layoffs relied on variation across industries.
} 
Table 2: MTC Estimates Based on the Industry-specific Actual Average UI Tax Rates

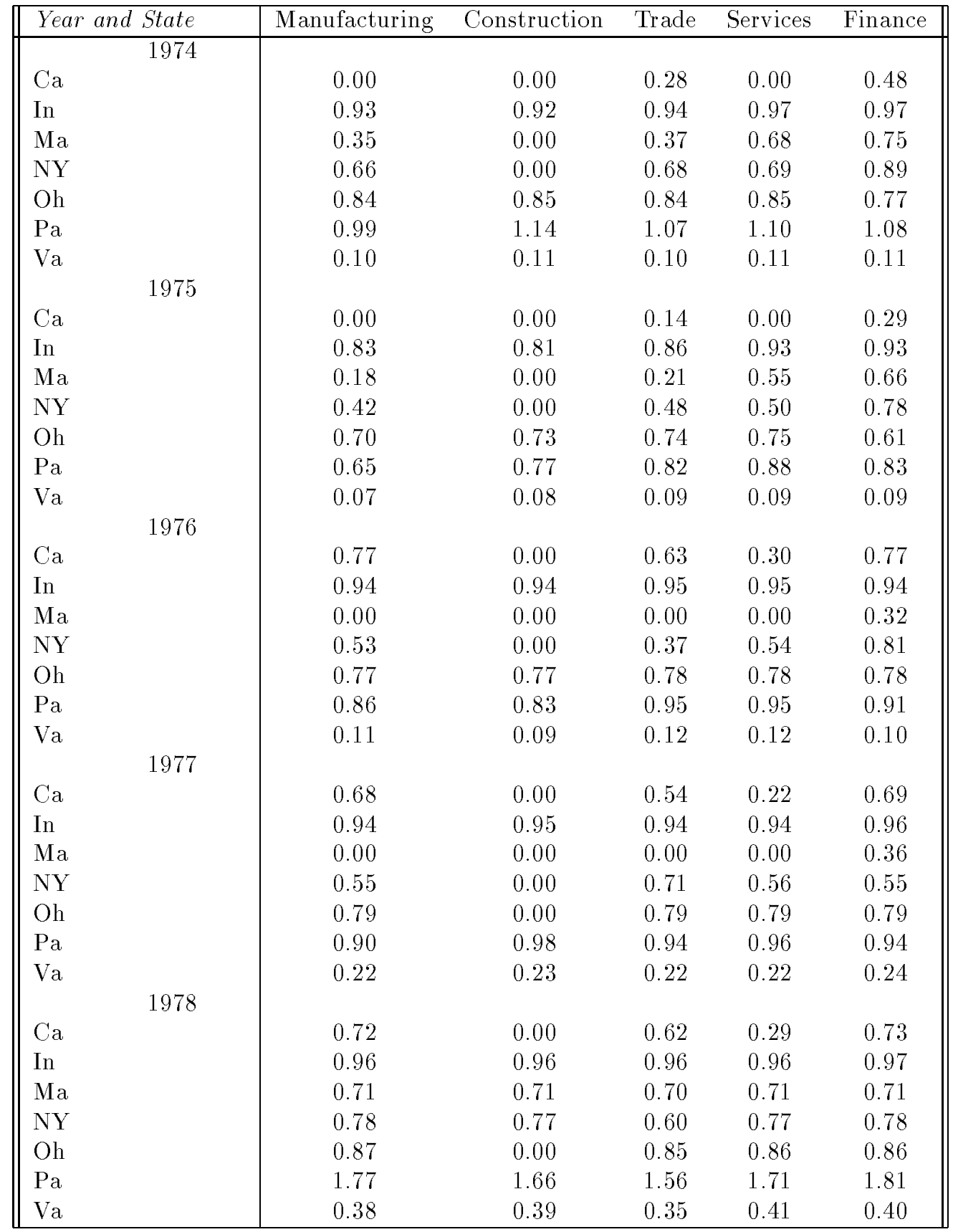

this additional subsidy to layoffs. The extent to which firms are experience rated therefore varies over the duration of an unemployment spell. With the detailed information available 
in the data set we are able to impute individual UI eligibility status and the amount of available benefits for each worker at each point in time. This is important in the estimation of experience rating effects as laid off workers not eligible for UI compensation do not bring any additional charges to the firm. Finally, workers who exhaust their regular benefits again bring no charges to the firm. While the estimates of MTC in Table 2 are comparable to previous studies, adjusting the experience rating measure to the other sources of imperfect experience rating results in only $34 \%$ of the weekly observations of unemployment for UI recipients having positive values of $\mathrm{MTC}^{15}$

\section{Estimation and Results}

\subsection{Duration Model}

The use of hazard models for analyzing duration data has become widespread. The duration model builds upon the concept of a hazard function which is defined as the probability of leaving a given state at duration $t$ conditional upon staying there up to the duration $t$. Using this definition one can build up a likelihood function for the observed durations and estimate it using standard methods.

More specifically, let $\lambda_{j}\left(t, x_{t}\right)$ be the conditional probability (hazard) of leaving a given state at time (duration) $t$ for someone with person specific characteristics $x_{t}$. The $j$ subscript stands for the different ways of leaving a given state. For example one can leave unemployment for a new job or for a recall in which case $j \in\{r, n\}$. This is often referred to as a competing risk model. We work in discrete time with weekly hazards in logit specification:

$$
\lambda_{j}\left(t, x_{t}\right)=\frac{1}{1+e^{-h_{j}\left(t, x_{t}\right)}}
$$

\footnotetext{
${ }^{15}$ While most of this drop in the measured extent of experience rating is caused by exhaustion of benefits, one should take the magnitude of the drop as an upper bound estimate due to the sample design of the TAA dislocated workers survey which includes multiple spells. The likelihood that a given employer is not liable is higher in fresh employment spells and those in turn are over-represented in our sample.
} 
where

$$
h_{j}\left(t, x_{t}\right)=r_{j}\left(e_{t}, \alpha_{j}\right)+\beta_{j}^{\prime} z_{t}+g_{j}\left(t, \gamma_{j}\right)
$$

Here, $r_{j}\left(e_{t}, \alpha_{j}\right)$ denotes a function of remaining entitlement $e_{t}, x_{t}^{\prime}=\left(e_{t}, z_{t}^{\prime}\right)$, where the vector $z_{t}$ includes levels of benefits, wages, demographics, time changing demand measures and a constant. ${ }^{16}$ Finally, $g_{j}\left(t, \gamma_{j}\right)$ is a function capturing the duration dependence. One can think of $\lambda_{j}\left(t, x_{t}\right)$ as being an approximation to a continuous time hazard specified as $\exp \left\{h_{j}\left(t, x_{t}\right)\right\}$.

To give an example of how the sample likelihood is evaluated using the concept of a hazard function assume the competing risks away for now. Let $\lambda$ denote the overall hazard out of a given state. In absence of any unobserved heterogeneity, the likelihood function contribution for someone leaving unemployment at duration $t$ would be

$$
L(t)=\lambda\left(t, x_{t}\right) \prod_{v=1}^{t-1}\left[1-\lambda\left(v, x_{v}\right)\right] .
$$

In a competing risks specification with new job and recall hazards, the unconditional probability of someone leaving unemployment through a recall at duration $t$ would become

$$
L_{r}(t)=\lambda_{r}\left(t, x_{t}\right) \prod_{v=1}^{t-1}\left[1-\lambda_{r}\left(v, x_{v}\right)\right]\left[1-\lambda_{n}\left(v, x_{v}\right)\right],
$$

where $\lambda_{r}$ and $\lambda_{n}$ denote the recall and new job hazards respectively. Similarly, for someone who finds a new job in the week $t$ of an unemployment spell the likelihood contribution becomes

$$
L_{n}(t)=\lambda_{n}\left(t, x_{t}\right) \prod_{v=1}^{t-1}\left[1-\lambda_{r}\left(v, x_{v}\right)\right]\left[1-\lambda_{n}\left(v, x_{v}\right)\right] .
$$

The hazard models are natural for dealing with the problem of right-censoring. For an unemployment spell which is still in progress at the end of our sampling frame (i.e. no transition out of unemployment has been observed) one enters the survival probability:

$$
S(T)=\prod_{v=1}^{T}\left[1-\lambda_{r}\left(v, x_{v}\right)\right]\left[1-\lambda_{n}\left(v, x_{v}\right)\right] .
$$

\footnotetext{
${ }^{16}$ In all of the formulas we do not use individual $i$ subscript in order to streamline notation.
} 
Here, $T$ denotes the highest duration at which we observe the spell in progress and $S(T)$ gives the probability of a given spell lasting at least $\mathrm{T}$ periods. The sample likelihood then equals the product of individual likelihood contributions.

Detailed estimation strategy issues are discussed in Section 4.2. We do not present estimation results controlling for effects of unobserved heterogeneity, but in a preliminary analysis we have estimated a subset of specifications which did include unobserved factors using the flexible approach of Heckman and Singer (1984). Using a discrete mixing heterogeneity distribution with two points of support had little effect on the parameter estimates of interest.

\subsection{Hazard Function Estimates}

The theoretical model of Section 2 suggests that the impact of the UI system on recall decisions depends on the relative magnitudes of per-period tax cost of layoff, UI compensation, and the training costs. The measure of experience rated layoff costs used in previous studies is the marginal tax cost (MTC), which measures the fraction of a dollar paid in UI benefits to a laid off worker that the firm has to pay in future taxes. We believe this to be a crucial component of the appropriate measure of worker-specific UI layoff costs. The cost the firm is likely to consider in the weekly recall decision, though, is the weekly tax cost, which is the product of the MTC with the weekly UI benefit amount (WBA). We therefore compare results based on this measure to those using the traditional measure of experience rating.

We have direct information on the generosity of UI compensation and condition on it in the estimation. We lack, however, any direct measure of the training costs and proxy for those using industry dummies and worker demographics (age and education in particular). Controlling for industry structure is also crucial for a proper interpretation of the estimated experience rating effects. For example, most firms in the construction industry are typically at the maximum UI tax rate and are therefore not experience rated, but one would not want 
to interpret that as the cause of frequent temporary layoffs in the industry. We therefore condition on both a detailed set of industry dummies ${ }^{17}$ and on the industry specific national monthly unemployment rate. All specifications also include state unemployment rate averages and monthly deviations from these state specific means to control for permanent and temporary differences in local demand conditions. In all specifications we also enter the TAA dummy as well as a set of annual dummies.

Both the effect of UI entitlement and the duration dependence are parametrized as step functions. We include 5 entitlement steps chosen to cover similar fractions of transitions out of unemployment. ${ }^{18}$ Step functions in duration are also based on the observed transitions and the length of each step is determined to cover about $5 \%$ of exits. We have experimented with richer parametrizations $(2.5 \%)$ with no effect on any of the other coefficients. These semiparametric specifications do not impose any functional form restrictions.

Table 3 presents a set of estimates from the unemployment hazards. Let us first focus on the UI coefficients of interest. Column (1) lists the recall hazard UI coefficients from a typical specification not controlling for the effect of UI taxes. Weekly UI entitlement depresses the recall hazard and the estimated adverse effect is strongest at medium values (14-39) of remaining weeks of UI compensation. There appears to be no effect of the dollar value of UI benefits on recalls. While having worked for a firm where a TAA petition was approved raises the chances of re-employment there, not being entitled to UI compensation makes recalls less likely. More educated people are less likely to be hired by their previous employer and, conditional on other covariates, having been previously recalled decreases further recall chances. Temporary increases of the state unemployment rate make recalls

\footnotetext{
${ }^{17}$ Apparel and footwear, other nondurable manufacturing, automobile, steel, other durable manufacturing, finance, retail trade, and construction.

${ }^{18}$ The first two steps, i.e. 1-13 and 14-26, also control for collection of regular UI benefits. This is potentially important since after exhausting the regular benefits, MTC equals zero for all workers irrespectively of the firm's experience rating. This parameterization should prevent the estimated tax cost coefficients from capturing a potential effect of collecting regular benefits.
} 
less likely, while we are unable to estimate effects of long-term demand conditions proxied by the state average of unemployment rate. Conditional on local unemployment and on the industry and annual dummies, there appears to be no effect of the national industry-specific unemployment rate. These estimates are in general accord with those of existing studies.

Column (2) presents estimates including the $\mathrm{MTC}^{*}$ WBA coefficient capturing the weekly UI tax costs of layoff. The estimated effect is positive in the recall hazard, confirming the theoretical prediction of our model. When we enter the MTC alone, not interacted with the WBA, its coefficient is positive, but only marginally significant. ${ }^{19}$ Inclusion of the UI tax cost did not affect the other parameters with the exception of one of the UI entitlement coefficients which now becomes significant at $10 \%$ level. One would expect the UI tax cost of layoff to affect especially the recall probability of those workers who are on temporary layoff. ${ }^{20}$ It would be ideal to condition on a temporary layoff dummy, but the data set does not include information on recall expectations of workers. We can proxy an indicator of temporary layoff by a dummy equal to one when the worker was recalled in the previous spell of unemployment, since having been previously recalled is suggestive of an employment position in a firm which uses the strategy of temporary layoffs and recalls. We therefore estimated a specification where the weekly tax cost measure is interacted with the previousrecall dummy and with the no-previous-recall dummy, while conditioning on the previousrecall dummy itself. The effect of the tax cost on recall for those who had been previously recalled is larger and precisely estimated at 0.873 with a corresponding $t$ ratio of 4.2 . The tax cost has no discernible effect on those who had not been previously recalled (coefficient estimate of -0.219 with a $t$ ration of 0.8 ). The other coefficients are virtually identical to those in column $(2)^{21}$ and for the sake of brevity are not reproduced.

\footnotetext{
${ }^{19}$ The MTC coefficient estimate equals 0.245 with a corresponding $t$ ratio of 1.31 . The full set of results is available upon request.

${ }^{20}$ In our theoretical model we reflect this fact by focusing on firm employment decisions for a fixed roster of workers.

${ }^{21}$ Except the previous recall dummy coefficient, which increases to -0.265 and is still precisely estimated.
} 
Table 3: UI tax costs in the Exit from Unemployment Hazard Functions

\begin{tabular}{|c|c|c|c|c|}
\hline \multirow{2}{*}{$\begin{array}{l}\text { Type of Hazard } \\
\text { Variable }\end{array}$} & \multicolumn{2}{|c|}{ Recall } & \multicolumn{2}{|c|}{ New Job } \\
\hline & (1) & $(2)$ & (3) & (4) \\
\hline \multicolumn{5}{|c|}{ UI Coefficients } \\
\hline Weekly Tax Cost & - & $\begin{array}{l}0.422^{* *} \\
(0.198)\end{array}$ & - & $\begin{array}{l}-0.185 \\
(0.215)\end{array}$ \\
\hline Entitlement over 52 & $\begin{array}{l}-0.304 \\
(0.260)\end{array}$ & $\begin{array}{l}-0.348 \\
(0.262)\end{array}$ & $\begin{array}{c}-1.124^{* * *} \\
(0.286)\end{array}$ & $\begin{array}{c}-1.095^{* * *} \\
(0.288)\end{array}$ \\
\hline 39 to 52 & $\begin{array}{l}-0.371 \\
(0.254)\end{array}$ & $\begin{array}{r}-0.436^{*} \\
(0.257)\end{array}$ & $\begin{array}{c}-0.593^{* *} \\
(0.256)\end{array}$ & $\begin{array}{c}-0.549^{* *} \\
(0.261)\end{array}$ \\
\hline 27 to 39 & $\begin{array}{c}-0.586^{* *} \\
(0.257)\end{array}$ & $\begin{array}{c}-0.644^{* *} \\
(0.260)\end{array}$ & $\begin{array}{c}-0.535^{* *} \\
(0.255)\end{array}$ & $\begin{array}{c}-0.491^{*} \\
(0.260)\end{array}$ \\
\hline 14 to 26 & $\begin{array}{c}-0.766^{* * *} \\
(0.264)\end{array}$ & $\begin{array}{c}-0.825^{* * *} \\
(0.267)\end{array}$ & $\begin{array}{l}-0.397 \\
(0.252)\end{array}$ & $\begin{array}{l}-0.354 \\
(0.257)\end{array}$ \\
\hline 01 to 13 & $\begin{array}{l}-0.351 \\
(0.267)\end{array}$ & $\begin{array}{l}-0.415 \\
(0.270)\end{array}$ & $\begin{array}{c}0.129 \\
(0.244)\end{array}$ & $\begin{array}{c}0.177 \\
(0.249)\end{array}$ \\
\hline TAA Dummy & $\begin{array}{c}0.334^{* * *} \\
(0.115)\end{array}$ & $\begin{array}{c}0.520^{* * *} \\
(0.147)\end{array}$ & $\begin{array}{c}-0.179 \\
(0.153)\end{array}$ & $\begin{array}{c}-0.235 \\
(0.166)\end{array}$ \\
\hline Non-eligible Dummy & $\begin{array}{c}-1.255^{* * *} \\
(0.234)\end{array}$ & $\begin{array}{c}-1.223^{* * *} \\
(0.235)\end{array}$ & $\begin{array}{c}-0.959^{* * *} \\
(0.168)\end{array}$ & $\begin{array}{c}-0.975^{* * *} \\
(0.169)\end{array}$ \\
\hline Weekly Benefits & $\begin{array}{c}0.008 \\
(0.135) \\
\end{array}$ & $\begin{array}{l}-0.004 \\
(0.137) \\
\end{array}$ & $\begin{array}{c}-0.561^{* * *} \\
(0.195) \\
\end{array}$ & $\begin{array}{c}-0.550^{* * *} \\
(0.195) \\
\end{array}$ \\
\hline \multicolumn{5}{|c|}{ Demographics } \\
\hline Weekly Wage $* 10^{-2}$ & $\begin{array}{c}0.024 \\
(0.046)\end{array}$ & $\begin{array}{c}0.019 \\
(0.047)\end{array}$ & $\begin{array}{l}0.108^{* *} \\
(0.048)\end{array}$ & $\begin{array}{l}0.110^{* *} \\
(0.047)\end{array}$ \\
\hline Years of Education $* 10^{-1}$ & $\begin{array}{c}-0.333^{* *} \\
(0.147)\end{array}$ & $\begin{array}{c}-0.333^{* *} \\
(0.148)\end{array}$ & $\begin{array}{c}0.217 \\
(0.175)\end{array}$ & $\begin{array}{c}0.218 \\
(0.175)\end{array}$ \\
\hline Male Dummy & $\begin{array}{c}0.021 \\
(0.094)\end{array}$ & $\begin{array}{c}0.013 \\
(0.095)\end{array}$ & $\begin{array}{c}0.197^{*} \\
(0.110)\end{array}$ & $\begin{array}{c}0.199^{*} \\
(0.110)\end{array}$ \\
\hline Age $* 10^{-1}$ & $\begin{array}{c}0.282 \\
(0.186)\end{array}$ & $\begin{array}{c}0.276 \\
(0.186)\end{array}$ & $\begin{array}{c}-0.489^{* *} \\
(0.238)\end{array}$ & $\begin{array}{c}-0.489^{* *} \\
(0.238)\end{array}$ \\
\hline Age $\mathrm{SQ} * 10^{-2}$ & $\begin{array}{l}-0.021 \\
(0.023)\end{array}$ & $\begin{array}{l}-0.002 \\
(0.023)\end{array}$ & $\begin{array}{c}0.041 \\
(0.030)\end{array}$ & $\begin{array}{c}0.041 \\
(0.030)\end{array}$ \\
\hline Previously Recalled Dummy & $\begin{array}{c}-0.153^{* *} \\
(0.073) \\
\end{array}$ & $\begin{array}{c}-0.163^{* *} \\
(0.073) \\
\end{array}$ & $\begin{array}{c}-0.956^{* * *} \\
(0.111) \\
\end{array}$ & $\begin{array}{c}-0.949^{* * *} \\
(0.112) \\
\end{array}$ \\
\hline \multicolumn{5}{|c|}{ Demand Conditions } \\
\hline $\begin{array}{l}\text { Average of State Unemployment } \\
* 10^{-1}\end{array}$ & $\begin{array}{c}-0.071 \\
(0.439)\end{array}$ & $\begin{array}{c}0.008 \\
(0.448)\end{array}$ & $\begin{array}{l}1.65^{* * *} \\
(0.475)\end{array}$ & $\begin{array}{c}1.556^{* * *} \\
(0.487)\end{array}$ \\
\hline $\begin{array}{l}\text { Deviations from Average State } \\
* 10^{-1}\end{array}$ & $\begin{array}{c}-1.462^{* * *} \\
(0.458)\end{array}$ & $\begin{array}{c}-1.42^{* * *} \\
(0.458)\end{array}$ & $\begin{array}{l}-0.442 \\
(0.486)\end{array}$ & $\begin{array}{l}-0.451 \\
(0.487)\end{array}$ \\
\hline $\begin{array}{l}\text { National Industry Unempl. Rate } \\
* 10^{-1}\end{array}$ & $\begin{array}{c}0.195 \\
(0.254)\end{array}$ & $\begin{array}{c}0.222 \\
(0.255)\end{array}$ & $\begin{array}{c}0.028 \\
(0.021)\end{array}$ & $\begin{array}{c}0.019 \\
(0.213)\end{array}$ \\
\hline Log-Likelihood & 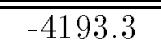 & 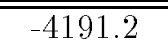 & 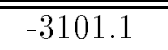 & -3100.7 \\
\hline
\end{tabular}


In column (3) we list the new job hazard estimates for parameters of interest. The negative impact of UI entitlement is larger for high values of entitlement and becomes smaller as workers near exhaustion of benefits. Unlike in the recall hazard, higher UI benefits make workers search less intensively and lower the probability of new job findings. Collecting the TAA benefits also has a negative albeit imprecisely estimated effect on the new job hazard. The effect of not being eligible for UI is somewhat lower compared to the recall hazard, but still sizeable and precisely estimated. Having higher wages and being a male increases the likelihood of finding a new job, while older people are less likely to be successful in their job search. Previous recall makes new job findings less likely and the effect is much more pronounced here than in the recall hazard. We obtain a puzzling estimate of the effect of demand conditions as higher long term unemployment makes one more likely to find a new job. ${ }^{22}$ Finally, the degree to which a previous employer is charged for the UI benefits has a negative, imprecisely estimated effect on the probability of finding a new job with an alternative firm. Further, neither the MTC alone, nor the weekly tax cost interacted with previous recall dummy could be significantly estimated and the inclusion of the experience rating controls did not affect other parameter estimates.

Table 4 reports the baseline hazard coefficients capturing duration dependence. For the sake of brevity only estimates from specifications in columns (2) and (4) of Table 3 are presented. Both hazards exhibit negative duration dependence as they decrease over time at a relatively stable rate with the exception of very long durations where the exit probability increases. All of the baseline hazard coefficients are precisely estimated in both hazards.

\footnotetext{
${ }^{22}$ One possible explanation is that the state average unemployment effect may be confounded with the pure state-specific effects since we do not condition on a set of state dummies.
} 
Table 4: Baseline Hazards Estimates for Table 3

\begin{tabular}{||c|cc|cc||}
\hline Type of Hazard & \multicolumn{2}{|c|}{ Recall } & \multicolumn{2}{|c||}{ New Job } \\
\hline Variable & $(2)$ & $(4)$ \\
\hline \hline \multicolumn{4}{|c||}{ Weekly Baseline Hazards } \\
\hline Duration 1 to 2 & -4.89 & $(0.686)$ & -3.16 & $(0.713)$ \\
3 to 4 & -5.17 & $(0.687)$ & -3.87 & $(0.723)$ \\
5 to 6 & -6.08 & $(0.694)$ & -4.07 & $(0.729)$ \\
7 to 8 & -6.61 & $(0.705)$ & -4.88 & $(0.756)$ \\
9 to 11 & -6.41 & $(0.697)$ & -4.02 & $(0.723)$ \\
12 to 14 & -6.46 & $(0.703)$ & -4.52 & $(0.734)$ \\
15 to 18 & -6.82 & $(0.708)$ & -4.60 & $(0.730)$ \\
19 to 24 & -6.71 & $(0.700)$ & -4.62 & $(0.722)$ \\
25 to 28 & -7.04 & $(0.718)$ & -4.88 & $(0.735)$ \\
29 to 33 & -6.88 & $(0.709)$ & -4.80 & $(0.726)$ \\
34 to 38 & -6.90 & $(0.708)$ & -4.92 & $(0.729)$ \\
39 to 44 & -7.05 & $(0.704)$ & -5.32 & $(0.733)$ \\
45 to 53 & -7.72 & $(0.714)$ & -5.14 & $(0.720)$ \\
54 to 71 & -7.70 & $(0.694)$ & -5.41 & $(0.715)$ \\
72 to 92 & -8.32 & $(0.721)$ & -5.34 & $(0.713)$ \\
93 to 122 & -8.39 & $(0.731)$ & -5.94 & $(0.735)$ \\
123 to 170 & -7.54 & $(0.708)$ & -5.89 & $(0.759)$ \\
171 and over & -6.48 & $(0.751)$ & -5.25 & $(0.856)$ \\
\hline Standard errors in parentheses. All of the coefficients are sig-
\end{tabular}

\section{Conclusion}

There is no previous empirical evidence on the effect of UI taxes on unemployment durations. The present study employs methods similar to those used in the existing literature on unemployment duration to look at how the UI financing system affects the duration of employment and unemployment. Assigning the degree of experience rating to unemployed workers over the duration of their spells revealed a number of interesting facts indicating a zero extent of experience rating in certain cases irrespective of the firm's past history of layoffs. These further reductions in our measure of experience rating combined with approximately $50 \%$ of the sample coming from TAA firms, which are not liable for UI benefits paid to their former employees, made the fraction of observations with positive value of the extent of experience rating very small. 
In the estimation procedure, we used parameterizations of the experience rating measure that are in accord with the underlying structural decision problem of firms. The estimated recall hazard coefficients are suggestive of behavioral importance of experience rating for the recall decisions, especially for firms which use the strategy of adjusting employment by temporary spells of recall unemployment. This is in accord with the prediction of our theoretical model, which suggested that conditional on the magnitudes of UI compensation and the training costs, higher per-period tax cost of keeping workers on layoff should make recalls more likely.

We believe that the results presented in this paper motivate future studies utilizing richer representative data sets. In particular, it would be ideal to work with both the firm specific tax rate as well as an indicator of recall expectation at the start of an unemployment spell. Future research should also be explicit in modeling the potential dynamic interaction of the experience rating effect with the numerous extended benefits programs. Such interaction effect could arise since firms are typically not liable for UI benefits paid under these programs and since a large fraction of those workers who start collecting UI under any of the extended benefits programs stays in unemployment until they exhaust all of the available UI compensation (see Jurajda and Tannery, 1998). Firms could be comparing the UI tax cost of the remaining weeks of regular UI benefits being collected by the worker to the expected benefit of having the worker available for recall for an extended period of time at no additional cost. 


\section{References}

Anderson, P. M. (1992), "Time-Varying Effects of Recall Expectations, a Reemployment Bonus, and Job Counseling on Unemployment Duration,"Journal of Labor Economics, 10: 99-115

Anderson, P.M. and B.D. Meyer (1994), "The Effects of Unemployment Insurance Taxes and Benefits on Layoffs Using Firm and Individual Data,”NBER Working Paper No. 4960.

Atkinson, A. and J. Mickelwright (1991), "Unemployment Compensation and Labor Market Transitions: A Critical Review,"Journal of Economic Literature, 29:1629-1727.

Azariadis, C. (1975), "Implicit Contracts and Underemployment Equilibria," Journal of Political Economy, $83: 1183-1202$.

Baily, M.N. (1977), "On the Theory of Layoffs and Unemployment,"Econometrica, 45:1043- 1063.

Baker, M. and S.A. Rea (1993), "Employment Spells and Unemployment Insurance Eligibility Requirements," unpublished paper, University of Toronto.

Becker, S.J. (1981), "Unemployment Insurance Financing," Washington, DC: American Enterprise Institute.

Burgess, P.L. and S.A. Low (1992), "Unemployment Insurance and Employer Layoffs," Unemployment Insurance Occasional Paper 93-1, U.S. Department of Labor.

Card, D. and P.B. Levine (1992): "Unemployment Insurance Taxes and the Cyclical and Seasonal Properties of Unemployment," National Bureau of Economic Research Working Paper Number 4030.

Card, D. and P.B. Levine (1994): "Unemployment Insurance Taxes and the Cyclical and Seasonal Properties of Unemployment," Journal of Public Economics, 53:1-29.

Christofides, L.N. and C.J. McKenna (1996), "Unemployment Insurance and Job Duration in Canada," Journal of Labor Economics, 14:286-312.

Corson, W. and W. Nicholson (1981), "Trade Adjustment Assistance for Workers: Results of a Survey of Recipients Under the Trade Act of 1974," Research in Labor Economics, 4:417-469.

Devine, J. and N. Kiefer (1991), “Empirical Labor Economics,”(Oxford: Oxford University Press).

Fallick, B. (1991), "Unemployment Insurance and the Rate of Re-employment of Displaced workers," Review of Economics and Statistics, May, 73(2):228-35.

Feldstein, M.S. (1976), "Temporary Layoffs in the Theory of Unemployment,"Journal of Political Economy, $84: 837-857$.

Ham, J. and S.A. Rea (1987), "Unemployment Insurance and Male Unemployment Duration in Canada," Journal of Labor Economics, 325-353.

Imbens, G. and L.M. Lynch (1993), "Re-employment Probabilities over the Business Cycle," NBER Working Paper No. 4585.

Jurajda, S̆. (1998), "Inflow into Unemployment: Employment Spells and Unemployment Unsurance," Working Paper No. 130, Prague: CERGE-EI. 
Jurajda, S̆., and F. Tannery (1998), "Unemployment Spells and the Extended Unemployment Benefits in Local Labor Markets," Working Paper No. 129, Prague: CERGE-EI.

Katz, L. and B. Meyer (1990a), "Unemployment Insurance, Recall Expectations, and Unemployment Outcomes," Quarterly Journal of Economics, November, 973-1002.

Lancaster, T. and S. Nickell (1980), "Reemployment Probabilities for the Unemployed," Journal of the Royal Statistical Society, A.

Mortensen, D.T. (1977), "Unemployment Insurance and Job Search Decisions," Industrial and Labor Relations Review, 30:505-517.

Pissarides, C.A. (1982), "Job Search and the Duration of Layoff Unemployment," Quarterly Journal of Economics, 97:595-612.

Topel, R.H. (1983), "On Layoffs and Unemployment Insurance," American Economic Review, 73:541-559. 